Gut, 1984, 25, 183-187

\title{
Corrosive acid ingestion in man - a clinical and endoscopic study
}

\author{
J B DILAWARI, SURJIT SINGH, P N RAO, AND B S ANAND \\ From the Departments of Gastroenterology and Internal Medicine, Postgraduate Institute of Medical \\ Education and Research, Chandigarh, India
}

SUMMARY Sixteen patients with corrosive acid ingestion were studied. The majority of patients $(n=10)$ had ingested sulphuric acid, and three other patients had ingested hydrochloric acid. The extent and severity of upper gastrointestinal tract injury was determined by fibreoptic endoscopy and necropsy. All the patients had oesophageal and gastric involvement but the duodenum was spared in the majority. The injury was not considered as mild (grade I) in any of these patients; five patients having moderate (grade II) and 10 patients having severe (grade III) injury. Complications and mortality occurred only in patients with grade III injury. Feeding jejunostomy for nutritional support was used in five patients (all grade III) with good results.

Knowledge on the corrosive injury of upper gastrointestinal tract owing to alkali ingestion is adequate. ${ }^{1-4}$ On the other hand reports on acid injury of upper gastrointestinal tract are scanty and these mainly consist of case reports. ${ }^{5-7}$ In a review of English literature from 1960 to 1978 , Chodak and Passaro collected only 25 cases of acid ingestion. ${ }^{8}$

Fibreoptic endoscopy in corrosive burns of upper gastrointestinal tract is regarded not only as a safe procedure but also provides information regarding the extent and severity of the injury which ultimately has bearing on the treatment and prognosis of the condition. ${ }^{9-11}$ This is a prospective study of 16 patients with acid ingestion describing the spectrum of injury, the clinical outcome, and response to treatment.

\section{Methods}

PATIENTS

Sixteen adult patients with diagnosis of corrosive acid ingestion were admitted to the Nehru Hospital of Postgraduate Institute of Medical Education and Research, Chandigarh, India during the period from January 1978 to December 1980 (three years). Data were collected prospectively and relevant information was recorded on a specially designed register. Emergency fibreoptic endoscopy was carried out in

Address for correspondence: J B Dilawari, Associate Professor, Department of Gastroenterology, Postgraduate Institute of Medical Education and Research, Chandigarh-160012, India.

Received for publication 22 April 1983
13 patients within 24 hours of hospital admission using forward viewing fibre endoscope (Olympus GIF $\mathrm{P}_{2}$ ). Necropsy findings were available in three patients; one of whom also had had endoscopy. The mucosal burns were graded arbitrarily into three grades: mild (grade I) mucosal hyperaemia; moderate (grade II) superficial ulcerations; severe (grade III) extensive and deep ulcerations. Recognition of various grades of injury through the endoscope was not difficult except in patients with borderline grade III injury.

We describe here the treatment and subsequent course of corrosive acid ingestion. The follow up period was from three to 24 months.

\section{Results}

AGE, SEX, AND SOCIO-ECONOMIC STATUS

The mean age was 27 years (range 16-60 years). There were 12 men and four women. All of them belonged to low socio-economic status. In eleven patients the injury was accidental while in five patients it was a suicidal attempt.

NATURE AND AMOUNT OF AGENT INGESTED AND TIME INTERVAL BEFORE ADMISSION TO THE HOSPITAL

The commonest corrosive acid ingested was sulphuric acid $(n=10)$ followed by hydrochloric acid $(n=3)$. Other corrosive acids ingested were nitric acid, formic acid and chromic acid (one each). As no 
endoscopy was performed on the patient who ingested chromic acid this is not included in the Tables. The mean time interval between ingestion and admission to the hospital was 14 hours (range 1-48 hours) except in one patient where the time interval was 120 hours. The amount of acid ingested in eight patients varied from $15-40 \mathrm{ml}$. In the remaining eight patients this information was not available. The concentration of acids ingested by our patients is not known. As our patients obtained acids from the market, chemical analysis of these showed hydrochloric acid to be in the range of $7 \cdot 48 \mathrm{~N}-9 \cdot 50 \mathrm{~N}$ (maximum concentration $13 \cdot 1 \mathrm{~N}$ ) and sulphuric acid to be in the range of $26 \cdot 40 \mathrm{~N}-35 \cdot 40 \mathrm{~N}$ (maximum concentration $36 \cdot 8 \mathrm{~N}$.

\section{SYMPTOMS AND SIGNS}

Epigastric pain and vomiting occurred in 15 (94\%) and $14(88 \%)$ patients respectively. Haematemesis and oropharyngeal burns were observed in $12(75 \%)$ patients. The patient who ingested chromic acid developed intravascular haemolysis and acute renal failure.

\section{ENDOSCOPIC FINDINGS}

Endoscopy was carried out in 13 patients. The mean time interval between ingestion and endoscopy was 21 hours (range nine to 32 hours). Oesophageal damage was mild (grade I) in two, moderate (grade II) in six, and severe (grade III) in five patients. Damage was more severe at the lower end of oesophagus whereas the proximal part of oesophagus was relatively spared. Stomach injury was moderate (grade II) in five, and severe (grade III) in eight patients. The maximum involvement of stomach was along the lesser curvature and in the region of the antrum.

The duodenum was involved in only four patients, in all of whom it was mild (grade I).

\section{NECROPSY FINDINGS}

Necropsy was performed in three patients. In patient no 10 (Table 1) who was endoscoped and on whom a necropsy was performed, the findings were similar. The remaining two patients, where endoscopy was not carried out, showed grade III injury involving oesophagus, stomach, and duodenum.

Thus based on endoscopic and necropsy findings, five patients were classified as having grade II injury and 10 patients grade III injury. The amount of acid ingested dịd not correlate with the severity of the lesion.

\section{MANAGEMENT, COMPLICATIONS AND MORTALITY} Patients with moderate (grade II) injury (Table 2)

There were five patients in this group. During the first 48-72 hours they were kept on intravenous fluids and nothing was given by mouth. They were then gradually put on oral feeds, starting with liquids. Four of the five patients in this group were given antibiotics (ampicilline $500 \mathrm{mg}$ intravenously, 6 hourly) and corticosteroids (dexamethasone $4 \mathrm{mg}$ intramuscularly 6 hourly) for seven days. During the follow up period of three to six months no complications were observed as assessed by clinical and radiological evaluation.

Patients with severe (grade III) injury (Table 1)

There were 10 patients in this group. All of them

Table 1 Patients with severe (grade III) injury

\begin{tabular}{|c|c|c|c|c|c|c|c|c|c|c|c|c|}
\hline \multirow[b]{2}{*}{ No } & \multirow{2}{*}{$\begin{array}{l}\text { Agent } \\
\text { ingested }\end{array}$} & \multirow[b]{2}{*}{ Cause } & \multicolumn{3}{|c|}{$\begin{array}{l}\text { Extent and severity } \\
\text { of injury }\end{array}$} & \multirow[b]{2}{*}{ Therapy } & \multirow[b]{2}{*}{ Outcome } & \multirow{2}{*}{$\begin{array}{l}\text { Follow up } \\
\text { (months) }\end{array}$} & \multicolumn{2}{|c|}{ Complications } & \multicolumn{2}{|c|}{ Surgery } \\
\hline & & & Oes & Stom & Duod & & & & Early & Late & Early & Late \\
\hline $1^{*}$ & $\mathrm{H}_{2} \mathrm{SO}_{4}$ & Accident & III & III & III & A S & Died & - & Bron & - & - & - \\
\hline $2^{*}$ & $\mathrm{H}_{2} \mathrm{SO}_{4}$ & Accident & III & III & III & A & Died & - & GP & - & - & - \\
\hline 3 & $\mathrm{H}_{2} \mathrm{SO}_{4}$ & Accident & III & III & 0 & A S & Survived & Lost & - & - & - & - \\
\hline 4 & $\mathrm{H}_{2} \mathrm{SO}_{4}$ & Suicide & II & III & 0 & A S FJ & Survived & Six & $\mathrm{H}$ & Ant St & - & GR \\
\hline 5 & $\mathrm{H}_{2} \mathrm{SO}_{4}$ & Accident & II & III & I & A S FJ & Survived & 12 & - & Ant St & - & GR \\
\hline 6 & $\mathrm{H}_{2} \mathrm{SO}_{4}$ & Suicide & III & III & 0 & A S FJ & Survived & 24 & - & Oes St & - & CBP \\
\hline 7 & $\mathrm{H}_{2} \mathrm{SO}_{4}$ & Accident & III & III & I & A S & Survived & 3 & GP & Oes St & C & SR \\
\hline 8 & $\mathrm{H}_{2} \mathrm{SO}_{4}$ & Accident & III & III & I & A S & Survived & 24 & - & Oes St & - & St D \\
\hline 9 & $\mathrm{Hcl}$ & Accident & III & III & 0 & A S FJ & Survived & 5 & - & Oes St & - & St D \\
\hline $10 \dagger$ & $\mathrm{HNO}_{3}$ & Suicide & II & III & 0 & A S FJ & Died & - & GP TLO & - & $\mathrm{C}$ & - \\
\hline
\end{tabular}

* Extent of injury determined by necropsy only.

+ Extent of injury determined by endoscopy and necropsy.

$\mathrm{A}=$ antibiotics, $\mathrm{S}=$ steroids, $\mathrm{H}=$ haematemesis, $\mathrm{C}=$ closure, $\mathrm{GP}=$ gastric perforation, $\mathrm{FJ}=$ feeding jejunostomy, $\mathrm{GR}=$ gastric resection, $\mathrm{SR}=$ surgery refused, $\mathrm{TLO}=$ transient laryngeal oedema, $\mathrm{ATN}=$ acute tubular necrosis, $\mathrm{CBP}=$ colon by pass, $\mathrm{St} \mathrm{D}=$ stricture dilitation, Bron=bronchopneumonia, Ant $\mathrm{St}=$ antral stricture, Oes $\mathrm{St}=$ oesophageal stricture. 
Table 2 Patients with moderate (grade II) injury

\begin{tabular}{|c|c|c|c|c|c|c|c|c|c|c|c|c|}
\hline \multirow[b]{2}{*}{ No } & \multirow{2}{*}{$\begin{array}{l}\text { Agent } \\
\text { ingested }\end{array}$} & \multirow[b]{2}{*}{ Cause } & \multicolumn{3}{|c|}{$\begin{array}{l}\text { Extent and severity } \\
\text { of injury }\end{array}$} & \multirow[b]{2}{*}{ Therapy } & \multirow[b]{2}{*}{ Outcome } & \multirow{2}{*}{$\begin{array}{l}\text { Follow up } \\
\text { (months) }\end{array}$} & \multicolumn{2}{|c|}{ Complications } & \multicolumn{2}{|c|}{ Surgery } \\
\hline & & & Oes & Stom & Duod & & & & Early & Late & Early & Late \\
\hline 1 & $\mathrm{Hcl}$ & Accident & I & II & 0 & A S & Survived & 3 & - & - & - & - \\
\hline 2 & $\mathrm{Hcl}$ & Accident & I & II & 0 & Antacid & Survived & 6 & - & - & - & - \\
\hline 3 & $\mathrm{H}_{2} \mathrm{SO}_{4}$ & Suicide & II & II & 0 & A S & Survived & 3 & - & - & - & - \\
\hline 4 & $\mathrm{H}_{2} \mathrm{SO}_{4}$ & Accident & II & II & 0 & A S & Survived & 4 & - & - & - & - \\
\hline 5 & Formalin & Accident & II & II & I & A S & Survived & 6 & - & - & - & - \\
\hline
\end{tabular}

$\mathrm{A}=$ antibiotics, $\mathbf{S}=$ steroids.

were given intravenous fluids and nothing by mouth. Antibiotics were given to all patients, and corticosteroids were given to nine of them. Five patients had early major complications; gastric perforation (three); massive haematemesis (one) and severe bronchopneumonia (one). Among the five patients with early major complications two did not have endoscopic examination and in the remaining three patients complications occurred after five, six, and 11 days after endoscopy. Endoscopic procedure did not contribute to any of these major complications. Early surgery was carried out in two patients (closure of gastric perforation) and one died. In total there were three deaths (two with gastric perforation and one with severe bronchopneumonia) in this group. Two patients died within three days ( 46 hours and 70 hours) of acid ingestion, and one patient died after 23 days.

Feeding jejunostomy was started within two to three days of hospital admission in five of the seven surviving patients. A total of 2000-2500 calories being given through a jejunostomy tube.

In this group, late complications developed in all six who were available for follow up (five to 24 months); oesophageal stricture in four, and antral stenosis in two. One of the four patients with oesophageal stricture had colonic bypass. Two patients had successful endoscopic dilatation with Eder Puestow dilators. In the remaining fourth patient the oesophagus was so narrow that even a guide wire could not be passed through. Resection of stricture and colonic bypass was advised but surgery was refused and he left the hospital against medical advice. Two patients with antral stenosis had successful resection of the stricture with relief of gastric outlet obstruction.

\section{Discussion}

Corrosive burn of upper gastrointestinal tract due to acid ingestion is common in India. During this period of prospective study (three years) all patients admitted because of corrosive poisoning had ingested acid only, and none had ingested alkali. This is because mineral acids are used commonly as cleansing agents in Indian households and are available freely in the market at very low cost. Sulphuric acid was ingested in the majority (10/16) of our patients. In contrast corrosive acid ingestion is rare in the west and among the collected case reports published the agent most frequently ingested was hydrochloric acid $(14 / 25){ }^{8}$

The grade of injury did not correlate with the type of acid or its concentration. Although our information about acid concentration is based on the samples obtained from the market, we believe that these concentrations do represent the actual concentrations of acids swallowed by our patients because they obtained the acids from a similar source.

The degree of mucosal damage did not relate to whether acid ingestion was suicidal or accidental. This may be because information given regarding the mode of acid ingestion was not reliable as suicide attempts have medicolegal implications in India.

Contrary to traditional belief that the oesophagus is spared in acid ingestion, ${ }^{8}$ we found oesophageal damage of moderate (II) to severe (III) grade in 13 out of 15 patients. DiCostanzo et al have also observed oesophageal involvement in 11 out of 12 patients with acid ingestion, although the degree of damage in their patients was not specified. ${ }^{11}$ This finding of almost universal involvement of the oesophagus seen in our patients as well as in those of DiCostanzo and coworkers could well be the result of early endoscopic examination of upper gastrointestinal tract in these cases.

Early endoscopic grading of the injury caused by corrosive acid has not only helped in planning the management of patients but also in predicting the prognosis. All five patients endoscopically classified to have grade II (moderate) injury did not develop early or late complications, although all the 10 patients with grade III (severe) injury had complica- 
tions (early or late). Early major complications occurred in five out of 10 patients and three of these five died. In none of our patients did early endoscopy contribute to any complications. Late complications occurred in all six patients (oesophageal structure - four, and antral stricture two) who were available for follow up. DiCostanzo et al, in a similar study of 76 patients with endoscopic grading of the lesion, recorded complications and mortality only in patients with grade III injury. ${ }^{11}$ It is interesting to note that the incidence of grade III injury in patients with acid ingestion in their series ${ }^{11}$ was similar to ours. Seven $(58.3 \%)$ out of 12 patients with acid ingestion in their series ${ }^{11}$ and $10(62.5 \%)$ out of 16 patients in our series had grade III injury. This is in contrast with only seven $(10.8 \%)$ out of 64 patients with alkali and bleach ingestion having grade III injury. ${ }^{11}$ These data suggest that acid ingestion causes more severe injury to the upper gastrointestinal tract than alkali.

The duodenum, however, was spared in the majority of our patients. This sparing of duodenum could be because of pyloric spasm induced by the acid, and also because of neutralisation of acid by alkaline contents of duodenum.

The true incidence of oesophageal and gastric complications is difficult to assess in the reported series as these are mainly case reports. We found oesophageal stricture in four $(35 \%)$ out of 11 patients available for follow up. Gastric complications occurred in five $(33 \%)$ out of 16 patients (perforation three, and stricture two).

We cannot compare our mortality rate of $18.7 \%$ (3/16) with any published series as almost all reports deal with lye ingestion apart from one where 12 out of 76 patients with corrosive injury had ingested acid, and two of these 12 patients died, giving a mortality rate of $16 \% .^{11}$

There is no controlled prospective study on the use of corticosteroids in prevention of stricture formation in man where the mucosal injury has been graded before corticosteroids were given. The only evidence that corticosteroids and antibiotics given early in experimentally induced lye burns prevent oesophageal strictures are in rabbits, dogs, and cats. ${ }^{12-14}$ No such data, however, are available in animals with acid ingestion. In a recent study of 76 patients mostly with alkali and bleach ingestion, managed without corticosteroids, oesophageal stricture occurred only in $7 \%$ of the patients. ${ }^{11}$ This is no greater than previously reported incidences of oesophogeal stricture in patient with lye ingestion treated with corticosteroids. ${ }^{11516}$

In our study 13 (four with grade II and nine with grade III) of 15 patients were treated with adequate doses of corticosteroids and antibiotics. Complications occurred (both early and late) only in patients with grade III injury. It is unlikely that corticosteroids and antibiotics were helpful in grade II and not in grade III injury. From these data it seems likely that complications depend on the degree of burn rather than the use of corticosteroids.

The management depends on the degree of damage assessed by early endoscopy. In patients with mild (grade I) injury oral feeds can be permitted from the first day. In patients with moderate injury (grade II) liquids can be given orally after 48-72 hours. Patients with severe injury (grade III), however, were not allowed anything by mouth and feeding through jejunostomy tube was started after 48-72 hours. DiCostanzo et al advocate intravenous hyperalimentation in grade II and III injury until healing takes place. ${ }^{11}$ Patients with grade III injury required total parenteral nutrition for a period of up to 90 days. In developing countries like India, however, where cost and non-availability precludes the routine use of this form of therapy, feeding jejunostomy seems to be the rational approach for adequate nutrition.

Because of the danger of gastric perforation in grade III injury some workers advocate early gastric resection. ${ }^{8}$ Our data do not support this viewpoint, as only three out of 10 patients with grade III injury developed gastric perforation. The limit of resection is difficult to assess in acute cases and sutures may cause problems because of oedema and ulceration. ${ }^{17}$ In addition it will be difficult to predict how much healing is to occur at a later date in a given patient.

In conclusion this study shows that corrosive acid ingestion causes severe injury to the oesophagus and stomach. Early endoscopy helps in classification of the injury and in the subsequent management. Complications and mortality occur only in severe (grade III) injury. Feeding jejunostomy for nutritional support is required in this group only.

\section{References}

1 Balasegaram M. Early management of corrosive burns of the oesophagus. Bri J Surg 1975; 62: 444-7.

2 Ragheb MI, Ramdaan AA, Khalil MA. Management of corrosive oesophagitis. Surgery 1976; 79: 494-8.

3 Bikhazi HB, Thompson ER, Shumrick DA. Caustic ingestion: current status (a report of 105 cases). Arch Oto Laryngol 1969; 89: 770-3.

4 Citron BP, Pincus IJ, Geokas MC, Haverback BJ. Chemical trauma of the oesophagus and stomach. Surg Clin North Am 1968; 48: 1303-12.

5 Marks IN, Bank S, Werbeloff L, Farman J, Louw JH. 
The natural history of corrosive gastritis: report of five cases. Am J Dig Dis 1963; 8: 509-24.

6 Nicosia JF, Thornton JF, Folk FA, Saletta JD. Surgical management of corrosive gastric injuries. Ann Surg 1974; 180: $139-43$.

7 Herrington JL. Stenosis of the gastric and proximal duodenum resulting from the ingestion of corrosive agent. Am J Surg 1964; 107: 580-4.

8 Chodak GW, Passaro E Jr. Acid ingestion, need for gastric resection. JAMA 1978; 239: 225-6.

9 Anand BS, Singh S, Dilawari JB. Emergency gastrointestinal endoscopy in acute corrosive poisoning. Ind $J$ Med Res 1980; 72: 308-11.

10 Chung RSK, Denbesten L. Fibreoptic endoscopy in treatment of corrosive injury of the stomach. Arch Surg 1975; 110: 725-8.

11 DiCostanzo J, Noirclerc M, Jouglard J, Escoffier JM, Cano N, Martin J, Gauthier A. New therapeutic approach to corrosive burns of the upper gastro- intestinal tract. Gut 1980; 21: 370-5.

12 Rosenberg N, Kunderman PG, Vroman L, Moolten SE. Prevention of experimental oesophageal strictures by corrosives. Arch Surg 1953; 66: 593-8.

13 Weisskopf A. Effects of cortisone on experimental lye burn of the oesophagus. Ann Oto Rhino Laryngol 1952; 61: 681-9.

14 Haller JA, Bachman K. The comparative effect of current therapy on experimental caustic burns of the oesophagus. Pediatrics 1964; 34: 236-45.

15 Ray E, Morgan DL. Cortisone therapy of lye burns of the oesophagus. J Pediatr 1956; 49: 394-7.

16 Viscomi GJ, Beekhuis GJ, Whitten CF. An evaluation of early endoscopy and corticosteroid therapy in the management of corrosive injury of oesophagus. $J$ Pediatr 1961; 59: 356-7.

17 Chong GC, Beahrs OH, Payne WS. Management of corrosive gastritis due to ingested acid. Mayo Clin Proc 1974; 49: 861-5. 